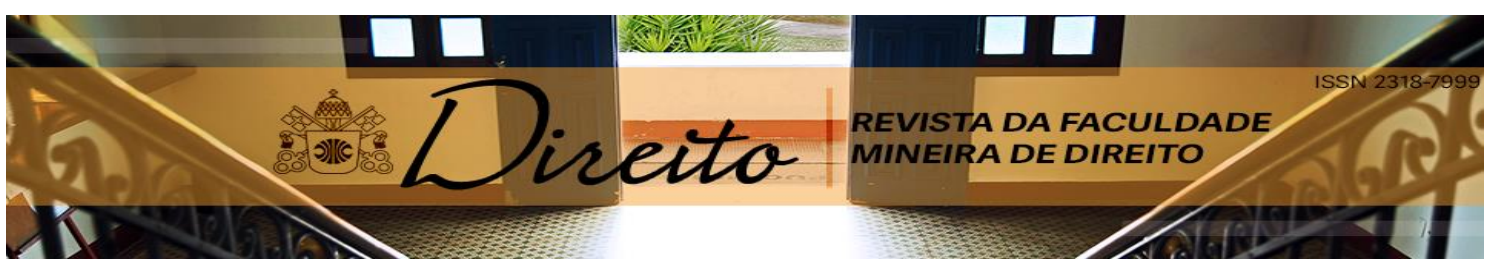

\title{
ESTADO GRAVÍDICO: LIMITAÇÕES IMPOSTAS À ENTREVISTA DE EMPREGO E PROTEÇÃO NO PRÉ-CONTRATO DE TRABALHO
}

\author{
PREGNANT: IMPOSED LIMITATIONS ON JOB INTERVIEW AND PROTECTION AT \\ WORK PRE- CONTRACT \\ Lara Caxico Martins Miranda ${ }^{1}$ \\ Lourival José de Oliveira ${ }^{2}$
}

\begin{abstract}
Resumo
A partir do método dedutivo, o estudo em questão aborda a aplicação dos princípios e diretrizes civilistas gerais acerca do contrato preliminar ao pré-contrato de trabalho e à entrevista de emprego. Sob esta fundamentação, visa solucionar questões pontuais atinentes à dispensa arbitrária de gestantes ainda nas fases preliminares da contratação. $O$ estudo em destaque analisa a aplicação das diretrizes civilistas no pré-contrato de trabalho e na entrevista de emprego, dando ênfase à responsabilidade decorrente dos danos causados nessa fase. Utilizando a pesquisa bibliográfica, o estudo aplicou toda a teoria firmada no direito civil ao caso de grávidas que deixam de ser contratadas por sua condição. Após a análise doutrinária e jurisprudencial, entendeu-se que, nos casos mencionados, aplica-se a estabilidade provisória da gestante, mesmo sem a efetivação do contrato de trabalho, tendo em vista os princípios da proteção do emprego e do nascituro.

Palavras-Chave: Entrevista de Emprego. Gravidez. Pré-Contrato de Trabalho. Responsabilidade.
\end{abstract}

\begin{abstract}
From the deductive method, the study in question deals with the application of civilists general principles and guidelines on the preliminary contract to work pre-contract and job interview. Under that reasoning, seeks to address specific issues relating to the arbitrary dismissal of pregnant women still in the preliminary stages of contracting. The study highlighted analyzes the application of the guidelines civilists at work pre-contract and job interview, emphasizing the liability for damage caused in this phase. Using the literature, the study applied the whole theory signed the civil law to the case of pregnant women who are no longer employed by their condition. After the doctrinal and jurisprudential analysis, it was understood that in the cases mentioned, applies to temporary stability of the pregnant woman, even without the execution of the employment contract, in view of the principles of employment and protection of the unborn child.
\end{abstract}

Key-words: Job Interview. Pregnancy. Responsibility. Work Pre-Contract.

Artigo recebido em 03 de setembro de 2016 e aprovado em 11 de novembro de 2016.

1 Mestranda em Direito pela Universidade Estadual de Londrina, Londrina, Paraná, Brasil.

2 Doutor em Direito pela Pontifícia Universidade Católica de São Paulo. Professor na Universidade Estadual de Londrina, Londrina, Paraná, Brasil. 


\section{INTRODUÇÃO}

A legislação trabalhista brasileira muito bem direciona a aplicação de outros ramos do Direito à ciência do trabalho. $O$ artigo 769 da Consolidação das Leis do Trabalho permite que nos casos em que a Lei seja omissa, haja a consideração subsidiária do direito processual comum ao direito processual do trabalho. Para que haja a aplicação, todavia, ressalta o legislador que não basta a omissão, mas também a compatibilidade da norma a ser utilizada com os princípios que regem o processo do trabalho. Isso significa em suma que a lei civilista precisa estar alinhada com o acesso do trabalhador à Justiça.

A doutrina moderna se consolidou no sentido de que não apenas as leis processuais civilistas poderiam ser aplicadas ao processo do trabalho, mas também as leis de materiais cíveis poderiam subsidiar as lacunas das leis materiais trabalhista. Conforme se verá no presente trabalho, a doutrina brasileira entende que a aplicação subsidiária se dá nas hipóteses de lacuna normativa, ontológicas e axiológicas. Ou seja, também a essência e o valor da norma poderiam ser aplicados frente aos vazios apresentados pela lei trabalhista.

Vale mencionar que a aplicação de normas da ciência civilista à ciência trabalhista não retira o caráter autônomo desta. Como se verá, o Direito do trabalho possui campo temático específico, teorias próprias e metodologia específica, requisitos definidos como essenciais para que uma determinada ciência seja considerada autônoma.

Nesse sentido o presente estudo pretende apresentar a aplicação dos princípios e regras atinentes ao contrato preliminar cível às contratações trabalhista, não deixando de lado o norte protetor do Direito do Trabalho. Isso se faz necessário porque a legislação trabalhista não define o pré-contrato de trabalho. Assim, a doutrina e jurisprudência trabalhista buscam respaldo conceitual no Direito Civil.

Observar-se-á através da análise aqui feita que a concepção de promessa de emprego, entrevista e propriamente as tratativas a respeito da contratação definitiva, se sustentam em definições da doutrina civilista, bem como do Código Civil. Até mesmo a responsabilidade, deriva do inadimplemento, traz em si a essência desta norma.

Após a profunda análise do contrato preliminar de trabalho, o estudo se debruçará na obrigação de indenizar no caso de danos causados na entrevista de emprego bem como no caso de prejuízos advindos do rompimento do pré-contrato de trabalho. Análise doutrinária e jurisprudencial evidenciará o caminho que os tribunais regionais trabalhistas e o Tribunal Superior do Trabalho têm trilhado diante de casos concretos que envolvem o tema.

Por fim, a análise culmina na discriminação das grávidas na entrevista de emprego, nos danos que podem ser causados e na responsabilidade da empresa que deixa de contratar uma mulher em virtude do estado gravídico. Além do impasse na fase das propostas, o trabalho trata das consequências advindas do rompimento do contrato preliminar em virtude da descoberta, por parte do empregador, da gravidez da sua futura empregada.

Não há na doutrina nem na jurisprudência posicionamento acerca do tema, entretanto sua análise se faz fundamental para que seja assegurado o valor social do trabalho (artigo 1ㅜ, 
IV, CF)e a proteção à maternidade consubstanciada na estabilidade concedida às gravidas desde a confirmação da gravidez até cinco meses após o parto (artigo 10, II, b, ADCT).

O estudo mencionado foi desenvolvido a partir do método dedutivo, ou seja, a partir das premissas estabelecidas para o contrato de trabalho preliminar no âmbito do direito civil deduziu-se logicamente quais princípios seriam aplicáveis ao pré-contrato de trabalho. Ademais, a partir da análise da doutrina e da jurisprudência acerca da responsabilização da empresa no caso de dispensa arbitrária durante o processo seletivo ou após firmado o contrato preliminar, buscou-se respostas para a aplicação da estabilidade provisória da gestante, mesmo sem a efetivação do contrato de trabalho.

\section{CONTRATO PRELIMINAR}

A Consolidação das Leis do Trabalho estabelece em seu artigo 442 que "contrato individual de trabalho é o acordo tácito ou expresso, correspondente à relação de emprego". Não há, porém, na legislação trabalhista, definição acerca do pré-contrato de trabalho. Dessa forma, necessário de faz para a ciência trabalhista, buscar respaldo conceitual no Direito Civil.

É plenamente aceito pela doutrina e jurisprudência a aplicação do Direito Civil nas relações trabalhistas diante de omissões legislativas e desde que haja compatibilidade com os princípios basilares do direito do trabalho. Neste caso, conforme se demonstrará, os princípios próprios do pré-contrato estabelecidos no âmbito civilista, não colidem com aqueles estabelecidos no âmbito trabalhista.

Primeiramente, cumpre esclarecer que a maior parte da doutrina brasileira opta pela utilização da expressão "contrato preliminar". Nessa esteira, cita-se Mário e Beviláqua. O civilista Miranda, por sua vez, se apropria do termo "pré-contrato". Esses são sem dúvidas as expressões que mais aparecem no âmbito trabalhista. Há ainda, porém, a possibilidade de se utilizar as expressões "promessa de contrato", "contrato preparatório", ou mesmo "compromisso", sem que erro algum haja.

Gonçalves muito bem explica que nem sempre o acordo de vontades que preconiza o contrato ocorre de modo instantâneo, imediato. Por diversas vezes o diálogo das partes resulta em prolongada discussão referente às negociações preliminares. Nem sempre é possível se obter uma proposta e pronta aceitação. Nessas situações podem as partes optar por realizar um contrato provisório ou preparatório com disposições acerca da complementação do ajustado (GONÇALVES, 2010, p. 161).

Ao final das tratativas, podem as partes desembocar em um contrato definitivo ou mesmo em um contrato preliminar. Segundo Diniz, o pré-contrato é o acerto entre duas ou mais pessoas acerca da celebração futura de um contrato. Trata-se de uma obrigação de fazer um contrato definitivo, contendo a possibilidade de arrependimento e indenização das perdas e danos (DINIZ, 2013, p. 862).

Para o civilista Silva Pereira, o contrato preliminar é "aquele por via do qual ambas as partes ou uma delas se comprometem a celebrar mais tarde outro contrato, que será o 
principal" (SILVA PEREIRA, 2004, p. 81). É possível se observar pela conceituação dos doutrinadores mencionados que os contratos preliminares têm como clássica característica a função de tornar obrigatória no futuro a contratação.

Enquanto que o contrato principal tem por objetivo uma relação jurídica realmente formada, criando, transferindo ou extinguindo direitos, o contrato preliminar tem como objetivo assegurar a formação futura dessa mesma relação. Assim o doutrinador prossegue dizendo que "diferencia-se o contrato preliminar do principal pelo objeto, que no preliminar é a obrigação de concluir o outro contrato, enquanto que o definitivo é uma prestação substancial" (SILVA PEREIRA, 2004, p. 81).

Segundo Monteiro é possível definir o contrato preliminar como uma convenção provisória entre as partes que contem necessariamente os elementos essenciais do contrato final. Este tem por objetivo concretizar em um futuro e em tempo oportuno um contrato definitivo (MONTEIRO, 2003, p. 69).

Por todo exposto, é certo que a única razão da existência do contrato preliminar é a possibilidade de formação de um novo contrato. Apesar disso, o contrato preliminar possui natureza própria, sendo considerado autônomo em relação ao contrato principal. Não se trata de mera fase do contrato principal, mas figura que se encontra no liame entre o contrato definitivo e as meras tratativas.

Por se constituir contrato autônomo, o professor Silva Ribeiro entende que este pode ter seu cumprimento exigido judicialmente, ainda que não tenha se firmado um contrato definitivo. Nessa linha, afirma que "o contrato preliminar (...) vincula as partes contratantes, obrigando-as a, na pior das hipóteses, responder por perdas e danos" (RIBEIRO, 2003, p. 49).

Cabe ainda mencionar que o contrato preliminar se distingue da simples oferta ou proposta. Ainda, as negociações preliminares em preparo do contrato não se configuram como pré-contrato. Segundo Caio Mário, nas negociações preliminares não há compromissos nem obrigações para os interessados. Nesse momento, as partes apenas analisam os interesses uma da outra. O contrato preliminar, por sua vez, determina parte a parte o contrato a ser firmado futuramente (SILVA PEREIRA, 2004, p. 81).

De modo claro, Venosa explica ainda que a oferta é a manifestação inequívoca da vontade de contratar, logo, enquanto não revogada, é obrigatória. As negociações preliminares, por sua vez, não representam vontade definitiva de efetivar o contrato. Observa-se que a lei dá força vinculativa à proposta (oferta), por isso a frustração dessa pode gerar um dever de indenizar, ainda que não seja um dever contratual. Quanto às negociações preliminares, explica Venosa que elas "não obrigam, enquanto não firmado o contrato" (VENOSA, 2005, p. 544).

Para o desenvolvimento do estudo, necessário se faz observar o conceito de preposta (oferta). Essa é a primeira fase do contrato que consta disciplinada na Lei. Existe na proposta a declaração de vontade do proponente em face do oblato. Para que o contrato preliminar se concretize basta que este último aceite (VENOSA, 2005, p. 545).

Como já mencionado, a proposta é vinculativa. A esse respeito, diz o artigo 427 do Código Civil que "a proposta de contrato obriga o proponente, se o contrário não resultar dos termos dela, da natureza do negócio ou das circunstâncias do caso". Por essa razão é claro que a frustração da proposta gera dano ao oblato e consequentemente dever de indenizar. 
Por fim, quanto ao objeto desse estudo, vale tratar acerca da responsabilidade civil cabível ao caso. Trata-se do que a doutrina e jurisprudência chamam de "dano de confiança" (VENOSA, 2005, p. 512). Dallegrave Neto fala sobre o tema:

O fundamento para a responsabilidade civil pré-contratual é a tutela da confiança negocial que propugna pela harmonia do comportamento das partes, solucionando eventual conflito entre a vontade e a declaração manifestada (DALLEGRAVE NETO, 2008, p. 108).

A responsabilidade emana de um contrato projetado, mas não concluído. Essa situação, como esclarece Venosa, primeiramente, coloca-se no âmbito sociológico. Ninguém está obrigado a vender, mas se essa pessoa se dispôs a tal, não pode recusar-se a fazê-lo a quem pretende adquirir o objeto de sua mercadoria. Isso porque essa conduta ultrapassa os limites do direito, constituindo-se prática abusiva e desvio de finalidade. "Como vemos, a questão relaciona-se com as regras gerais de convivência, os princípios da boa-fé e bons costumes, ainda que em fase não contratual" (VENOSA, 2005, p. 512).

Segundo Dallegrave Neto, há grande disputa doutrinária acerca da responsabilidade pré contratual e pós contratual. Para ele, é certo que ambas não se tratam de responsabilidade civil extracontratual, tendo em vista que na primeira hipótese ainda não há vínculo contratual e na segunda este já se extinguiu. Para ele tanto o dano pré-contratual quando o pós-contratual não decorrem da violação do objeto do contrato principal, mas sim de infração do princípio da boa-fé vinculada a atuação do sujeito (DALLEGRAVE NETO, 2008, p. 106).

O autor defende que a indenização decorrente da quebra das tratativas do contrato preliminar deve ser integral, porém não é a mesma daquela que seria devida no caso de o contrato principal ter sido celebrado. Ou seja, a reparação do dano pré-contratual atende ao chamado interesse negativo, que são as despesas e prejuízos relativos a não formação do contrato definitivo (DALLEGRAVE NETO, 2008, p. 107).

Fischer esclarece o que seria interesse negativo:

Por interesse contratual negativo entende-se, ao invés, aquele que deixa de invocar, para efeitos de indenização, a quem confiou na validade dum negócio que no fim de contas vem a ser nulo, quer em consequência de vício original quer por causas posteriores (FISCHER, 1938, p. 104-105).

Dallegrave Neto diz que o interesse negativo se relaciona a tudo que a parte deixou de ganhar em virtude das negociações, seja antes da concretização do pré-contrato de trabalho seja em virtude do seu rompimento. Podem se tratar de despesas relativas à negociação inicial ou do tempo gasto, referentes aos danos emergentes, ou aqueles referentes a oportunidades imediatas que a parte deixou de usufruir, ou seja, danos lucro cessantes, em virtude da proposta quebrada (DALLEGRAVE NETO, 2008, p. 107).

Observa-se assim que a simples quebra do contrato preliminar já presume a culpa em virtude do inadimplemento advindo de uma das partes. Isso porque uma das partes leva a outra a acreditar na futura contratação, logo esta despende de tempo e muitas vezes patrimônio se planejando para o contrato definitivo. Aquele se se retira injustificadamente da contratação preliminar causa dano àquele que queria firmar o contrato futuro.

$\mathrm{Na}$ esteira desse conhecimento Prata complementa: 
(...) os deveres pré-contratuais constituem imperativos de conduta destinados a satisfazer o interesse de sujeitos determinados (ou determináveis), o que, como se sabe, é o elemento que permite caracterizar as obrigações dos deveres jurídicos. Aliás, os deveres précontratuais não se configuram, como tipicamente acontece com os deveres cuja violação constitui ilícito extraobrigacional, por um conteúdo negativo, antes tendendo para a promoção e satisfação do interesse de um determinado sujeito (PRATA, 2005, p. 212).

Observa-se assim que a responsabilidade civil preliminar advém dos deveres de conduta pautados na boa-fé objetiva. O dever genérico de não prejudicar outrem nasce não do ordenamento jurídico, mas sim do dever de bom convívio social.

Para concluir, expõe-se que Venosa entende que, no caso de rompimento do contrato preliminar, devem ser indenizados os prejuízos materiais efetivos bem como os danos exclusivamente morais, pois a recusa de contratar gera vexame e constrangimento pessoal, que obviamente ocasionam danos morais (VENOSA, 2005, p. 512).

\section{PRÉ-CONTRATO DE TRABALHO}

Após o arrazoado, pode-se concluir que o contrato preliminar se trata de uma promessa de formação contratual definitiva futura. Em virtude de a maioria da doutrina entender ser este um contrato autônomo, tem-se que o inadimplemento de qualquer das partes faz nascer obrigação de indenizar caso haja prejuízo.

Após a caracterização do contrato preliminar segundo o Direito Civil, cumpre aplicá-lo ao contrato de trabalho. Segundo Oliveira, "diz-se preliminar a convenção em virtude da qual as partes assumem uma obrigação de fazer, consistente em realizar futuramente um contrato definitivo" (OLIVEIRA, 2002, p. 143). Segundo ele, há no direito do trabalho a possibilidade de se criar a "promessa de contratar". Esta, apesar de não prevista no direito Brasileiro, consta expressamente no Decreto-Lei n. 49.408 da legislação portuguesa:

Art. $8^{\circ}$. Promessa de contrato de trabalho.

1. A promessa de contrato de trabalho só é válida se constar de documento assinado pelo promitente no qual se exprima, em termos inequívocos, a vontade de se obrigar, a espécie de trabalho a prestar e a respectiva retribuição. 2. O não-cumprimento da promessa de contrato de trabalho dá lugar a responsabilidade nos termos gerais de direito. 3. Não é aplicável ao contrato de que trata este artigo o disposto no art. 830 do Código Civil (PORTUGAL, 1969).

Quanto à legislação portuguesa observa Orlando Gomes que enquanto no Brasil não há qualquer disposição na legislação trabalhista acerca do tema, em Portugal há, inclusive, determinação de que este se dê pela forma escrita. Há ainda, para que o contrato preliminar seja válido, que haja a declaração inequívoca da vontade de contratar, a estipulação das atividades e do valor a ser pago pelo serviço.

O pré-contrato de trabalho se forma quando da comunicação para o candidato da sua seleção para uma vaga de trabalho. Essa comunicação não necessariamente precisa ser formal. É possível se pensar na atualidade na comunicação por meios eletrônicos, como através de um telefonema ou e-mail. Afirma ainda que é possível que a informação sobre a seleção ocorra tacitamente, quando, por exemplo, o indivíduo é encaminhado para a realização de exames médicos admissionais, diante da retenção da carteira de trabalho e 
previdência social ou qualquer outra documentação necessária para a elaboração do contrato de trabalho (ZANGRANO, 2008, p. 645).

A necessidade do contrato preliminar se fez presente pelo fato de que nem todos os contratos de trabalho são firmados no momento em que a indicação da aprovação na seleção é feita. Na verdade, boa parte deles depende de entrega de documentos, aferição de aptidão em exames e abertura de contas. Nem sempre a formação do contrato preliminar é instantânea. Ainda assim não cabe confundir a proposta de contrato, que obriga o oblato, e a fase preliminar contratual (MARANHAO, 2000, p. 252).

Percebe-se, dessa forma, que o pré-contrato de trabalho pode ser tido como o período compreendido entre a notícia da intenção de contratação do empregado e a efetiva elaboração do contrato. Há o período de pré-contrato porque nem sempre este tem formação instantânea, como já tratado anteriormente. Trata-se da fase de pontuação ou negociações preliminares. A fase de pontuação é marcada pelas negociações acerca do que virá a ser o contrato de trabalho. As partes apontam, por exemplo, as condições e pretensões que lhes são convenientes (OLIVEIRA, 2002, p. 139).

Observa-se que o pré-contrato de trabalho nada se relaciona com a fase da seleção. Nesta não há responsabilidade do empresário. "Na fase de seleção, efetuada com lealdade, não há compromisso nenhum de admissão. Geralmente, o candidato aguarda uma chamada, ou para logo ser admitido ou para discutir condições concretas da ainda eventual admissão" (OLIVEIRA, 2002, p. 139).

Com relação aos seus requisitos, apesar de o Código Civil prever em seu artigo 463, parágrafo único, que o contrato preliminar deva ser levado a registro, é possível se concluir, a partir da análise do artigo 443 da CLT que não há essa exigência na relação laboral. Segundo o dispositivo mencionado, "o contrato individual de trabalho poderá ser acordado tácita ou expressamente, verbalmente ou por escrito (...)” (BRASIL, 2002).

Um dos princípios que regem a ciência trabalhista é a primazia da realidade. Segundo este, para constituição ou não de uma relação trabalhista é fundamental a análise real dos fatos, o que efetivamente ocorria no dia a dia laboral. Não se trata de desconsideração da prova documental, mas do seu detrimento frente à comprovação da realidade. Verifica-se a intenção do legislador de trazer um caráter de simplicidade às relações de trabalho.

Nesse sentido, para que seja reconhecida uma relação de emprego não se faz necessária a confecção de um contrato formal, escrito. Basta que sejam identificados os requisitos da relação de emprego: pessoalidade, onerosidade, habitualidade e subordinação.

Se há orientação, por parte do futuro empregador, do dia, horário e local do início das atividades laborais, entende-se que o contrato preliminar foi efetivamente formado. Isso porque há possibilidade de que o próprio contrato definitivo seja firmado de forma oral. Assim, caso as informações mencionadas sejam passadas, não é possível se entender que ainda exista um candidato, mas sim um empregado efetivamente à disposição do empregador para todos os efeitos da Lei Trabalhista (OLIVEIRA, 2002, p. 141). 
Tendo em vista que o contrato definitivo de trabalho não necessita ser escrito, aliado ao princípio da primazia da realidade e da disposição do artigo 443 da CLT, conclui-se que também não há obrigatoriedade que o contrato preliminar tenha forma escrita.

Dessa forma, pode-se concluir que o pré contrato de trabalho nasce quando passase para o indivíduo a informação de que ele foi aprovado para a vaga de emprego. Essa informação não precisa ser feita por escrito, nem exige maiores formalidades. A partir desse momento o futuro empregado buscará cumprir as exigências documentais indicadas até a formação perfeita do contrato definitivo.

\subsection{PRINCÍPIOS ATINENTES AO PRÉ-CONTRATO DE TRABALHO}

\subsubsection{A BOA FÉ OBJETIVA}

Antes da formação do contrato de trabalho há, como já amplamente tratado, o período de pontuação ou negociações preliminares em que o pré-contrato de trabalho é firmado. Neste momento, direitos e obrigações são criadas para ambas as partes, logo, por essa razão, não é possível se pensar em uma conduta fora dos padrões de lealdade e boa-fé. Nesta fase, há de ser resguardada a intimidade mútua, em razão da troca de informações pessoais. Cabe ainda às partes atuar com verdade e falar aquilo que realmente compreenderá o future contrato (OLIVEIRA, 2002, p. 139).

Estabelece o artigo 422 do Código Civil que "os contratantes são obrigados a guardar, assim na conclusão do contrato, como em sua execução, os princípios de probidade e boa-fé". Já o artigo 427 do mesmo diploma legal dispõe que "a proposta de contrato obriga o proponente, se o contrário não resultar dos termos dela, da natureza do negócio, ou das circunstâncias do caso" (BRASIL, 2002).

À luz dos princípios da proteção e do valor social do trabalho tem-se que se impõe aos contratantes a observância de um padrão de conduta ético, orientado pelos valores da lealdade, probidade e honestidade, que resumem o princípio da boa-fé objetiva. Essas orientações devem pautar o comportamento das partes desde a fase pré-contratual até depois da execução do contrato.

Há a necessidade de um ambiente de confiança entre as partes no momento da realização do pré-contrato de trabalho. Isso implica a necessária atuação com lisura, sinceridade e honestidade de vontades. Só assim é possível que o tempo gasto, e em alguns casos o dinheiro, realmente tenha significância. Agindo dessa forma certamente não haverá surpresa de uma das partes por uma attitude injustificada da outra (CAVALIERI FILHO, 2009, p. 284-285).

Por essa razão muitos autores defendem ser o princípio da boa-fé o grande fundamento da responsabilidade pré-contratual. Os deveres ali firmados vão do âmbito do convívio social até o campo das obrigações. O princípio da boa-fé vai além da mera contratação. Ele indica um dever social de considerar o outro sujeito da relação (DALLEGRAVE NETO, 2008, p. 106).

O dever de atuação conforme a boa-fé envolve diversas hipóteses. Dentre elas é possível citar que as partes não podem interromper o contrato injustificadamente, não podem celebrar um contrato preliminar inválido, nem mesmo celebrar um contrato válido sem atuar com verdade frente à informações. 
No âmbito do direito do trabalho, é possível pensar na primeira hipótese quando um candidato, após aprovado da seleção de emprego e encaminhado para exames médicos e abertura de conta, tem seu contrato rompido sem justificava plausível. A segunda hipótese é possível ser vista no caso da celebração de pré-contrato de trabalho para uma vaga inexistente. Nesse caso o contrato seria inválido por ausência de objeto.

Por fim, quanto a violação da boa-fé por falta de clareza nas informações, pode-se mencionar o empregado que aceita a vaga de emprego acreditando que exercerá determinada função e é direcionado, quando do início das atividades, para outra completamente diferente. Ainda, pensasse em pré-contrato que estipula valor de salário não compatível com aquela do contrato definitivo, ou em local de prestação de serviços diferente da anteriormente pactuada.

Em todos os casos tem-se a violação do princípio da boa-fé, que macula os contratos preliminares. Este impõe que não haja interrupção injustificada das tratativas, a concessão de informações leais e reais, o sigilo quanto àquelas recebidas da contraparte e não indução desta a erro. A violação das pontuações mencionadas importa em impossibilidade de realização do negócio ou sua invalidação (NORONHA, 2003, p. 456).

Pelo exposto, reitera-se que no âmbito das tratativas e da firmação do contrato preliminar é fundamental a tutela da confiança. Todos os homens devem portar-se com honestidade e lealdade não só nas relações parentais. Diante de uma proposta e aceitação de emprego é fundamental que ambas as partes tenham claro o que vão dar e o que vão receber.

\subsubsection{VINCULAÇÃO OU DA OBRIGATORIEDADE DA PROPOSTA}

A policitação é a primeira fase efetiva do contrato. O contrato preliminar é bilateral, ou seja, a proposta e a aceitação são declarações unilaterais de vontade que se consubstanciam em um contrato com obrigações para ambas as partes. A proposta sempre deve ser séria, clara e objetiva. Nenhuma das partes pode ficar com dúvidas acerca das cláusulas da proposta e consequentemente o que pode vir a conter no contrato definitivo. Dessa forma, tem-se que meras explanações ou ideias acerca do que possa vir a ser o contrato não se configuram em proposta válida e exigível.

Não é possível se confundir a proposta com as negociações preliminares. Nesta pode existir diversas propostas e contrapropostas, configurando um procedimento negociatório. Este muitas vezes não se finaliza no mesmo momento em que se inicia. A proposta final, por sua vez, não pode ser modificada, logo não há desta uma contraproposta.

No sistema civilista brasileiro a proposta é vinculativa da vontade do proponente. É certo que esta não gera vinculação eterna, mas sim por certo prazo e sob certas condições. Segundo o artigo 427 do Código Civil "a proposta de contrato obriga o proponente, se o contrário não resultar dos termos dela, da natureza do negócio, ou das circunstâncias do caso" (BRASIL, 2002).

Segundo Venosa "a proposta é vinculante, com efeitos concretos, sendo esses efeitos já disciplinados pela lei do consumidor. A formação do contrato diz respeito tanto aos interessados presentes quanto aos ausentes" (VENOSA, 2005, p. 547). A explanação gera a conclusão de 
que mesmo que a proposta seja realizada através de meio eletrônico, ela vincula a parte que a faz. Não há obrigatoriedade de presença física para que haja vinculação.

É preciso observar ainda a necessidade de que haja aceitação ou rejeição pela outra parte. Esta, assim como a proposta, não há necessidade de formalidades. Deve a parte contrária se ater a uma resposta simples e objetiva, que claramente se posiciona favoravelmente ou contrariamente à proposta. Há necessidade do cumprimento do requisito de tempestividade, caso este tenha sido mencionado pela parte adversa (VENOSA, 2005, p. 549).

No âmbito do direito do trabalho, cumpre esclarecer que a proposta com a respectiva aceitação vincula a contratação. Caso essa não seja realizada, gera o dever de indenizar, como se verá adiante no estudo. Ademais, a proposta ainda vincula os termos estabelecidos no contrato preliminar. Caso o empregador tenha se proposto a pagar um determinado salário e alocar o futuro empregado em determinada localidade, não pode alterar as condições quando da assinatura do contrato definitivo. Nesse sentido a jurisprudência dos nossos tribunais:

RECURSO ORDINÁRIO. PROPOSTA. VINCULAÇÃO AO CONTRATO DE TRABALHO. A proposta, como negociação preliminar à manifestação de vontade das partes, integra o contrato de trabalho e, consequentemente, as obrigações assumidas estão vinculadas ao contrato de trabalho celebrado e devem ser respeitadas (BRASIL, 2015).

Dessa forma, percebe-se que a empresa que deixa de cumprir a proposta apresentada viola princípio inerente ao contrato preliminar e causa dano àquele que criou expectativas acerca da contratação. Isso porque a proposta se constitui propriamente como o contrato preliminar de trabalho. Trata-se de ato ilícito que deve ser indenizado, conforme se verá.

\subsubsection{PROTEÇÃO À PRIVACIDADE}

A Constituição Federal de 1988 prevê em seu artigo 5º, inciso X, a tutela da intimidade e da vida privada. Demais direitos previstos no mesmo dispositivo legal, quais sejam, honra e imagem, derivam daqueles mencionados anteriormente. $O$ fundamento dessa proteção, entretanto, é a dignidade da pessoa humana, objeto de previsão constitucional como fundamento do Estado Democrático de Direito (art. 1ํㅡㄹ III da Constituição Federal de 1998).

Como princípio fundamental, a dignidade da pessoa humana é tida como norte para a execução de todo e qualquer outro princípio constitucional. Isso porque esta é característica inerente ao indivíduo, que merece respeito e consideração do seu valor como pessoa humana.

Silva muito bem explica a complexidade desse princípio:

Concebido como referência constitucional unificadora de todos os direitos fundamentais, o conceito de dignidade da pessoa humana obriga a uma densificação valorativa que tenha em conta o seu amplo sentido normativo constitucional e não uma qualquer idéia apriorística do homem, não podendo reduzir-se o sentido da dignidade humana à defesa dos direitos pessoais tradicionais, esquecendo-as nos casos de direitos sociais, ou invocá-la para construir "teoria do núcleo da personalidade" individual, ignorando-a quando se trate de garantir as bases da existência humana (SILVA, 2001, p. 105).

A proteção referente à intimidade e à vida privada se fundamenta no princípio da dignidade da pessoa humana. Assim, o respeito à essas deve ser parâmetro da conduta do Estado e dos demais particulares, sob pena de responsabilização.

A expressão "direito à privacidade" abarca noções da esfera íntima e de personalidade 
e pode ser identificada como o complexo de informações acerca do indivíduo (SILVA, 2001, p. 105). Intimidade, por sua vez, se refere ao núcleo da vida privada, onde se resguarda a individualidade (NUNES JUNIOR, 1997, p. 91-92).

Pode-se concluir assim que a intimidade é uma esfera mais íntima e a vida privada se relaciona a outros fatores mais ligados ao isolamento do indivíduo. No âmbito do indivíduo, podese dizer que seus sentimentos e pensamentos estão protegidos por serem de sua intimidade, enquanto que sua vida familiar está protegida por estar no âmbito da sua privacidade.

No contexto da entrevista de emprego é preciso lembrar que ambos os direitos devem ser totalmente protegidos. O candidato à vaga em uma empresa não pode ser obrigado a expor quaisquer informações íntimas que não estejam estritamente vinculadas à atividade a ser desenvolvida. Ademais, também não precisa passar informações acerca da sua família ou da sua vida pessoal, sob pena de caracterização de dano moral.

Em razão da hipossuficiência existente na relação empregatícia, muitas vezes esses direitos são violados no contrato de trabalho. É evidente que o indivíduo que passa por processo seletivo não se encontra em iguais condições que o empregador de negociar as cláusulas do contrato. Isso ocorre porque este, na maioria das vezes, depende do trabalho para a sua subsistência. Em virtude disso, é constantemente visto candidatos que aceitam quaisquer determinações impostas na seleção para conquistar a vaga de emprego almejada. O empresário, por outro lado, com o intuito de ter a melhor equipe de empregados, por vezes viola os direitos à intimidade e à privacidade do empregado. Fere assim a dignidade da pessoa humana e extrapola os meios utilizados no processo de seleção de pessoal.

Diversas razões podem levar o empresário a desrespeitar a intimidade e a vida privada de um indivíduo que esteja passando pelo processo seletivo. Dentre elas cita-se o interesse em conseguir o melhor funcionário para trabalhar em sua empresa e também a própria discriminação de não ter determinado tipo de pessoa trabalhando para si. Tais violações se dão através de uma pergunta abusiva ou um questionário. Há empresas que exigem certidões negativas de antecedentes criminais ou que realizam testes psicológicos com o intuito de verificar o perfil psicológico do candidato.

É possível que o empregador solicite informações sobre aptidões, experiências, disponibilidade de horário e até mesmo número de filhos, para o cálculo do pagamento de salário família. Não há impossibilidade de o empregador perguntar onde reside o candidato, se ele tem interesse em plano de saúde ou vale transporte. Percebe-se que se tratam de informações relacionadas exclusivamente ao emprego em questão. Perguntas invasivas e que não digam respeito ao trabalho podem gerar dano moral pela violação à vida privada e a honra.

BARACAT afirma que o empregador deverá:

(...) em princípio, abster-se de fazer perguntas ao candidato a respeito de origens raciais, opções políticas, convicções religiosas, atividades sindicais, bem como sobre circunstâncias pessoais capazes de gerar discriminação (...) necessário, também, que se reconheça ao candidato ao emprego o direito de ocultar circunstâncias alheias à causa contratual não relacionadas diretamente com o cargo que irá ocupar, diante de situações de imposição coativa (BARACAT, 2003, p. 232233). 
Como já mencionado, a legislação brasileira não prevê regra específica a ser seguida pelo empresário no momento da seleção pessoal. Não há uma lista de perguntas que podem e que não podem ser feitas. Apesar disso, a licitude dos atos no momento da seleção deve seguir o princípio da boa-fé, ética, proporcionalidade e razoabilidade. Só assim é possível verificar se no caso concreto o critério de seleção adotado foi discriminatório ou não.

\subsubsection{NÃO DISCRIMINAÇÃO}

Integram os objetivos fundamentais da República Federativa do Brasil promover o bem de todos, sem preconceitos de origem, raça, sexo, cor, idade e quaisquer outras formas de discriminação (art. $3^{\circ}$, inciso IV, da CF/88). O princípio da não discriminação se consubstancia a partir do princípio da igualdade, visto de modo positivo. A ligação entre eles encontra-se na vertente de igualdade de direitos que proíbe a discriminação injustificada.

É possível se pensar na não discriminação como evolução do princípio da igualdade. Entretanto, para a efetivação dos princípios é preciso estabelecer de modo preciso quais os momentos em que a discriminação é possível. Isso porque a adoção de medidas discriminatórias também iguala situações desiguais.

No âmbito do Direito do Trabalho, o artigo 7º, inciso XXX, CF, proíbe a diferenciação de salários, de exercício de funções e de critério de admissão por motivo de sexo, idade, cor ou estado civil. O mesmo artigo proíbe no inciso XXXI qualquer discriminação no tocante a salário e critérios de admissão do trabalhador portador de deficiência. Por fim, o inciso XXXII, dispõe acerca da proibição de distinção entre trabalho manual, técnico e intelectual ou entre os profissionais respectivos.

Em observância aos artigos mencionados, é notório que a Constituição Federal apresenta disposições claras acerca da vedação da discriminação no ambiente de trabalho e na entrevista de emprego. A proteção da igualdade no direito do trabalho não ficou restrita à Constituição, visto que o legislador, visando dar maior amplitude ao tema, positivou o princípio no texto infra constitucional.

Com relação ao tema, vale ainda mencionar a Convenção 111 da OIT, de 1959, aprovada pelo Brasil e promulgada pelo decreto n. 62.150/68. Este documento, que trata da discriminação em matéria de emprego e profissão, prevê que discriminação é toda forma de distinção, exclusão ou preferência que objetive alterar o tratamento destinado a determinada pessoa.

A Convenção mencionada esclarece que as distinções baseadas em qualificação exigida para determinado cargo não são consideradas discriminação. Isso se dá pelo fato de que algumas funções podem exigir perícia para a sua atuação, ou ainda, determinadas características físicas para o desenvolvimento da atividade.

Nesse sentido não é possível se pensar na contratação de uma mulher grávida para atuar com carregamento de peso, bem como um homem cego para atuar como porteiro. Não há discriminação quando a própria ocupação exige perfil, aptidão ou atributo para o seu desenvolvimento.

Ocorre discriminação quando há uma conduta segregacionista diante de indivíduos com a mesma capacidade profissional para o exercício da profissão. A discriminação contraria o princípio da igualdade entre os indivíduos. Atos de segregação demonstram preconceito 
exteriorizado pela pessoa, grupo, comunidade ou sociedade e representam uma distinção, exclusão ou preferência infundada, ou seja, não justificável.

Com relação à legislação infraconstitucional, a Lei n. 5.473/68 determina a nulidade de toda disposição que resulte em discriminações entre brasileiros para o provimento de cargos sujeitos à seleção nas empresas privadas e no serviço público. A Lei n. 9.029/95, na norma do artigo 1, também proíbe a adoção de "qualquer prática discriminatória e limitativa para efeito de acesso à relação de emprego", ou sua manutenção, por motivo de sexo, origem, raça, cor, estado civil, situação familiar ou idade.

Observa-se que a legislação pátria possui todo o amparo para resguardar o direito à não discriminação na entrevista de emprego. Assim, fácil é concluir que este parâmetro deve ser respeitado na fase de seleção e propostas. Caso haja violação por parte do contratante, há o dever de indenizar nos danos morais sofridos.

\section{A RESPONSABILIDADE NO PRÉ-CONTRATO DE TRABALHO}

$O$ início da fase de negociações preliminares traz para o empregado e para o empregador a expectativa da contratação. Logo, é natural que haja desejo legítimo de ambas as partes na conclusão do negócio. Em razão dessa expectativa, muitas vezes o candidato realiza despesas, abre mão de outras propostas de emprego ou altera planos de sua atividade atual. Em razão de situações como estas é que o contrato preliminar não pode ser frustrado por mero capricho do empregador, sem que haja o dever de indenizar nos prejuízos causados ao indivíduo que aguardava pela contratação (RODRIGUES apud OLIVEIRA, 2002, p. 138).

Nesse sentido, Cavalieri Filho (2009, p. 284-285) expõe a quebra das tratativa pode gerar o dever de indenizar não porque há um rompimento de contrato, mas sim porque fere-se o dever de transparência e boa-fé. Como princípios que regem os negócios jurídico, juntamente com o dever de cooperação e de informação, fundamentam a responsabilidade pré-contratual.

A fase preliminar das contratações começa a gerar obrigação a ambas as partes quando finda a seleção dos candidatos e se inicia as negociações preliminares. Neste momento, obrigações recíprocas são expostas, ficando o futuro empregado encarregado, normalmente, de entregar documentos e o futuro empregador de manter sua palavra frente à vaga de emprego. $\mathrm{Na}$ fase se seleção e entrevistas não é possível se falar em responsabilidade de indenizar, tendo em vista que as partes apenas estão se conhecendo. Ainda não há força vinculante nas exposições de ambos os lados, contudo, este processo pode atingir um determinado estágio em que a contratação daquela pessoa torna-se praticamente certa (KANEOYA, 2010).

Com relação às disposições legais acerca do tema, Gomes esclarece que, em comparação com o direito lusitano, há expressa previsão no Direito Português, conforme artigo $8^{\circ}$ do Decreto-lei 49.408, já mencionado, acerca da responsabilidade daquele que descumpre a obrigação preliminar. Observe:

Trata-se de compromisso bilateral. Uma das partes obriga-se a empregar a outra para a prestação, contra o pagamento de salários, de serviços especificados, e esta, a prestá-los, a partir de certo momento. $\mathrm{O}$ inadimplemento da obrigação fundamental de cada um dos contraentes antes de iniciada a execução do trabalho sujeita-o, no 
Ainda sobre a doutrina estrangeira, esclarece Barros que:

direito lusitano, ao pagamento de perdas e danos, seja ela quem prometeu empregar, seja quem prometeu trabalhar. Não há outra solução além desta de responsabilizar civilmente o devedor inadimplente, aplicando-se, de conseguinte, as regras da responsabilidade contratual (GOMES apud OLIVEIRA, 2002, p. 144).

A doutrina estrangeira também assevera que não há inconveniente em se aplicar os princípios da responsabilidade pré-contratual elaborados pelo Direito Civil para os casos em que, em virtude da atitude de uma das partes, configuradora de um claro abuso de direito, se produza um dano com a frustração do contrato de trabalho. Dá-se na hipótese "abuso da liberdade de não contratar", que constitui abuso de direito. Apesar de o contrato ainda não ter sido concluído, durante a negociação as partes devem agir com lealdade e boa-fé. A infringência desses deveres implica ressarcimento do dano emergente (gastos realizados) como também do lucro cessante que poderia ser obtido em outra contratação que não se concretizou, dada a frustração da negociação anterior, sem prejuízo da compensação pelo dano moral acaso verificado (BARROS, 2009, p. 654).

Apesar de não haver na legislação brasileira expressa cláusula acerca da responsabilidade do empregador quando do rompimento do pré-contrato de trabalho, a doutrina e jurisprudência tem se fixado no sentido de que é possível sim a cobrança dos danos materiais e morais a que tenha sofrido o trabalhador.

O descumprimento da obrigação pré-pactuada de contratar gera prejuízos àquele que esperava pelo emprego. Isso porque tanto o empregado quanto o empregador podem contrair dívidas, ou compor obrigações, contando com a efetivação do negócio. Não formando-o há o constrangimento que envolve o descumprimento das obrigações paralelas geradas (OLIVEIRA, 2002, p. 144).

No mesmo sentido coloca Cahali (1998, p. 464) que a desistência injustificada da contratação por gerar sérios prejuízos financeiros ao indivíduo que, por exemplo, deixou seu emprego antigo para iniciar naquele em que foi aprovado na seleção. É possível se pensar que uma pessoa possa até mesmo ter desprezado oferta de igual nível ou maior conveniência em virtude da promessa não concretizada.

Concorda com esse posicionamento Maranhão (2000, p. 241) ao lembrar que quando os entendimentos preliminares chegam a um ponto em que é certa a contratação e uma das partes rompe o contrato preliminar sem justo motivo é certo que a outra tem o direito ao ressarcimento do dano causado por esse rompimento. Não há, entretanto, esclarece o pesquisador, direito à indenização pelo simples rompimento, mas desde que seja possível provar que, confiando no ingresso no novo emprego, fez despesas, danos emergentes, ou deixou de aceitar outra oferta, lucros cessantes.

Com relação aos danos morais decorrentes da desistência injustificada de contratação pelo empregador há a necessidade de se analisar, em cada caso concreto, a sua aplicação. Não é pacífico que o simples rompimento gere o dever de indenizar, mas os prejuízos causados por este podem ensejá-lo. Aquele que, por ventura, tenha deixado outro trabalho em virtude da aprovação em processo seletivo, pode enfrentar inadimplementos de negócios jurídicos do dia a dia. Nessas situações o dano moral é claro e pode estar associado a danos materiais.

Quanto ao tema, vale ainda mencionar que a reparação ocorrerá nos moldes do direito civil, tendo em vista que a legislação trabalhista não regulamenta a matéria. A competência 
porém para julgamento, será da Justiça do Trabalho, em razão das disposições do artigo 114 da Constituição Federal. Destaca-se o estudo de Nascimento (1996, p. 209-210):

Problemas surgem quando há contrato escrito para início futuro da relação de emprego e esta não começa na data aprazada por oposição do empregador que, supervenientemente, desinteressouse do empregado. A lei não resolve a questão. Se resultarem prejuízos ao empregado, que contava com o emprego e se desfez de outras obrigações em função de ajuste com o novo empregador, o empregado terá direito às reparações que serão cíveis de acordo com o princípio da indenização por danos. A competência para apreciar a questão será da Justiça do Trabalho em face do disposto no art. 114 da Constituição Federal ao atribuir-Ihe poderes para resolver controvérsias oriundas das relações de emprego.

Por todo exposto é possível concluir que a obrigação de indenizar em virtude do précontrato de trabalho surge quando do início das negociações preliminares, ou seja, a partir do momento em que empregado toma ciência da sua contratação. A não formalização do contrato pelo empregador, após comunicação de aprovação no processo seletivo, caso ocorra sem justo motivação, gera a reparação dos prejuízos materiais e morais, pela empresa, junto a Justiça do Trabalho.

Após análise jurisprudencial, é possível constatar, nos últimos anos, aumento no número de ações perante a Justiça do Trabalho pleiteando indenização por danos pelo descumprimento do contrato preliminar de trabalho. Isso ocorre, na maioria das vezes, porque o candidato à vaga de emprego deixa o seu emprego atual com a expectativa da contratação, ou passa a assumir novas responsabilidades.

\section{RESPONSABILIDADE PRELIMINAR NA CONTRATAÇÃO DE GRÁVIDAS}

A Consolidação das Leis do Trabalho (CLT) estabelece em seu artigo 373-A que ressalvadas as disposições legais destinadas a corrigir as distorções que afetam o acesso da mulher ao mercado de trabalho e certas especificidades estabelecidas nos acordos trabalhistas, é vedado recusar emprego, promoção ou motivar a dispensa do trabalho em razão de sexo, idade, cor, situação familiar ou estado de gravidez, salvo quando a natureza da atividade seja notória e publicamente incompatível.

A garantia do acesso da grávida ao mercado de trabalho se estendeu com a edição da Lei 9.029 de 1995, que passou a proibir a exigência de atestados de gravidez, esterilização e quaisquer outras práticas discriminatórias em exames admissionais. Cassar (2014, p. 1189) reafirma a determinação legal em seus estudos:

Não pode o empregador obrigar a empregada a se submeter ao exame médico de esterilização ou de gestação, porque considerado crime pelo art. $2^{\circ}$ da Lei ํำ 9.029/95 e proibida a prática pelo art. 373-A, IV, da CLT. O exame médico periódico e demissional exigido pelo art. 168 da CLT não inclui o de sangue ou de urina, mas tão somente os superficiais ou os necessários para exercício da função.

As proteções citadas decorrem do valor social do trabalho, fundamento Constitucional (artigo 1ํ, IV , CF), do objetivo Constitucional de erradicar quaisquer formas de discriminação (artigo $3^{\circ}, \mathrm{IV}, \mathrm{CF}$ ) e da proteção à maternidade consubstanciada na estabilidade concedida às gravidas desde a confirmação da gravidez até cinco meses após o parto (artigo 10, II, b, ADCT). 
Assim, em virtude das proteções expostas, qualquer ato que impeça a mulher grávida a ter acesso a emprego, sem justificativa razoável, pode ser considerado discriminatório e ensejar o pagamento de indenização. É certo que tanto no momento da entrevista quanto após a formação do contrato preliminar de trabalho havendo preterição de uma candidata, a que o empregador soube que estava grávida, frente a outra que não estava, há dever de indenizar.

\subsection{A DISCRIMINAÇÃO NA ENTREVISTA DE EMPREGO}

O empregador possui, dente os seus poderes, a possibilidade de escolher quem ingressará no seu quadro de funcionários. Nada há erro em realizar entrevistas e processos seletivos visando à obtenção do melhor indivíduo para determinada vaga em uma empresa. Entendendo necessário, pode analisar currículos, fazer dinâmicas coletivas, exames de digitação, aplicar provas práticas e com isso verificar a habilidade do candidato (OLIVEIRA, 2002, p. 138).

É certo, porém, como menciona Barros, que não são permitidas análise de aptidões e perguntas totalmente alheias ao objeto da contratação. Observe:

O ordenamento jurídico brasileiro não possui uma norma dispondo sobre a licitude dos métodos utilizados na seleção de pessoal, sendo comum na entrevista os testes grafológicos, os questionários e os testes psicológicos. Quaisquer que sejam os métodos adotados, devese verificar sua aceitação ética e se limitar a avaliar a aptidão profissional do candidato. Informações sobre a esfera da vida privada do trabalhador só se permitem excepcionalmente, quando apresentam relevância para a execução dos funções que serão executadas, em nome da liberdade de contratação conferida ao empresário (BARROS apud OLIVEIRA, Paulo Eduardo, 2002, p. 138-139).

É evidente que muitos cargos não são compatíveis com o estado de gravidez, como funções que exijam carregamento de peso. No caso de a função ser estrita a pessoas com condições físicas específicas para a realização da tarefa, entende-se que cabe ao entrevistador ser claro acerca das atividades a serem realizadas, bem como das condições físicas necessárias para o seu desempenho.

De modo a garantir maior proteção à empresa que realizará o processo seletivo, podese pensar na realização de laudo técnico/médico que indique a função e as atividades a serem desempenhadas no cargo a ser preenchido. O mesmo pode especificar quem poderá realizar àquela função e quais as limitações pessoais. No caso tratado no presente estudo, importante seria delimitar que não é possível a realização do serviço por mulheres grávidas.

Havendo tal parecer, seria possível que o empregador realizasse uma investigação aprofundada acerca do estado ou não de gravidez da candidata ao emprego. Desse modo, caso posteriormente fosse tratado em Reclamatória Trabalhista suposta discriminação pelo estado de gravidez, a empresa estaria subsidiada de parecer médico que afastava a possibilidade de desenvolvimento daquela atividade por uma mulher grávida.

Ainda que uma mulher grávida não possa exercer a função para a qual a mulher se candidatou, entende-se que a empresa não pode forçá-la a fazer um teste de gravidez, mas deve consultá-la sobre a possibilidade de gravidez e, se ela estiver em dúvida, pedir sua autorização para fazer o exame. Esse entendimento se baseia na determinação constitucional constante no 
artigo 5ำ, Il que "ninguém será obrigado a fazer ou deixar de fazer alguma coisa senão em virtude de lei".

Ademais, o teste de gravidez pode causar constrangimentos à mulher e violação de sua intimidade. Havendo dano, ainda que moral, é cabível indenização.

Não havendo circunstâncias diferenciadas, durante o exame admissional não são permitidos testes de gravidez e de esterilização, constituindo-se crime esta prática discriminatória, conforme artigo $2^{\circ}$, II da Lei 9.029/95.

Nesse sentido a recente jurisprudência do Tribunal Regional do Trabalho da 4⿳亠丷a Região:

Preliminarmente. Contrarrazões da reclamante. Não conhecimento. Intempestividade. Não se conhece de contrarrazões interpostas fora do prazo legal. Mérito. Dano pré-contratual. Processo seletivo com exigência de exame de gravidez. Preterição de candidata grávida classificada no certame. Conduta ilícita e discriminatória perpetrada pela empresa prestadora de serviços. Impossibilidade de responsabilização subsidiária do ente público tomador dos serviços, por ausência de fundamento legal. Caso em que o Município de Tupanciretã contratou a $1^{\text {a }}$ reclamada tão somente para a 0 fornecimento de mão de obra terceirizada. Processo seletivo realizado por iniciativa única e exclusiva da $1^{\text {an }}$ ré, que não dispunha, de forma imediata, da mão de obra necessária para o cumprimento do objeto do contrato de prestação de serviços. Incontroversa a exigência de exame gravidez das candidatas classificadas. Não contratação da autora, que se encontrava grávida no momento de realização do processo seletivo, sucedendo-se a admissão de outra candidata, classificada em posição posterior à da reclamante.Evidente a prática, pela $1^{\text {a }}$ reclamada, de ato ilícito e discriminatório, ensejador de indenização por danos morais. Impossibilidade, contudo, de responsabilização subsidiária do ente público tomador dos serviços por ato praticado pela $1^{\underline{a}}$ ré em fase pré-contratual. Existência de dever de fiscalização apenas quando o contrato já se encontra perfectibilizado e em plena execução. Inteligência da Lei no 8.666/93 e da Súmula no 331 do TST. Inexistência de fundamentos legais para a manutenção da condenação subsidiária imposta na origem. Recurso provido (grifos nossos) (TRT4를, Relator: FLAVIO PORTINHO SIRANGELO, Data de Julgamento: 15/05/2013, Vara do Trabalho de Cruz Alta).

Assim também se colocam as decisões do Tribunal Regional do Trabalho da $5^{\mathrm{a}}$ Região, observe:

CONTRATO DE TRABALHO. ADMISSÃO DE TRABALHADORA CONDICIONADA Á APRESENTAÇÃO DE TESTE NEGATIVO DE GRAVIDEZ. ILICITUDE. DANO MORAL CUJA REPARAÇÃO SE IMPÕE. Condicionar a admissão de trabalhadora à apresentação de teste negativo de gravidez configura ilícito penal e trabalhista que corresponde na seara civil a grave lesão aos chamados direitos da personalidade, especialmente 0 direito à intimidade e à não discriminação, daí configurar-se adequada a reparação do dano moral decorrente (grifos nossos) (TRT 5스. R.; RecOrd 82374.2011.5.05.0017; Primeira Turma; Rela Des $^{\underline{a}}$ Ivana Mércia Nilo de Magaldi; DEJTBA 02/08/2012).

Vale frisar que a Lei anteriormente mencionada, não trata apenas da impossibilidade de exigir atestados de gravidez ou esterilização para a candidata em processo seletivo de emprego, mas sim veda expressamente quaisquer práticas discriminatórias em exames admissionais. 
Assim, também não é permitido que o examinador faça perguntas pessoais à candidata com o intuito de descobrir uma possível gravidez. A investigação prévia, qualquer que seja o critério adotado deve, em princípio, restringir-se a avaliar a aptidão do candidato para realizar as funções alusivas ao cargo que irá ocupar (BARROS, 1997, p. 61-67).

Não havendo impedimento para que mulheres grávidas atuem no cargo a ser preenchido através do processo seletivo, nenhuma pergunta a este respeito deve ser feita. Qualquer método escolhido deve ser analisado sob a égide da ética e da análise das aptidões para o trabalho. A liberdade de contratar conferida ao empregador só permite que este faça perguntas de ordem pessoal quando estas forem fundamentais para a execução da atividade. Deste modo, quaisquer perguntas que visam detectar aspectos da vida pessoal da candidata podem ser consideradas discriminatórias, cabendo indenização por dano moral em virtude da segregação.

Cabível ainda é a condenação em danos morais caso a empresa tenha conhecimento do estado gravídico da candidata, não a contrate por esse motivo e não justifique a desclassificação por outro motivo plausível ou venha a ser descoberto posteriormente o real motivo da desclassificação. Situação semelhante ocorreu e gerou o julgamento do Tribunal Regional do Trabalho da $2^{\text {a }}$ Região:

PROCESSO SELETIVO. APROVAÇÃO EM TODAS AS FASES. RECUSA INJUSTIFICADA DA CONTRATAÇÃO. FUNÇÃO SOCIAL DA EMPRESA. DANO MORAL. A faculdade de sujeitar os candidatos a processo seletivo prévio, composto por entrevistas e dinâmicas de grupo, é uma faculdade do empregador que deve ser exercida com observância dos direitos subjetivos dos trabalhadores. Aceita a forma de seleção pelos postulantes, cabe ao empregador, após a aprovação dos candidatos em todas as fases, implementar a contratação. Salvo a limitação de vagas, que deve ser comunicada de início, a recusa em admitir o postulante ao emprego, sem motivo justificado, importa subjetivismos que infligem danos imateriais aos lesados. A reparação deve levar em consideração, menos os aspectos subjetivos, e mais a penalização da empresa que não cumpriu com sua função social (TRT, $2^{\text {a }}$ Região, Ac. N. 20060494187, Recurso Ordinário, Processo n. 00500200406402001, Relator Rovirso Aparecido Boldo, Recorrentes: Venicios Valverde Mortess e Lojas Colombo S/a Julgado em: 12.06.2006.2).

É importante que o examinador tenha em mente que a seleção deve averiguar a qualificação, o potencial, a técnica e a motivação da candidata ao emprego. Questões de foro íntimo da candidata não podem ser abordadas no momento da entrevista, sob pena de violação do artigo 5, X da CF.

Dessa forma, ainda na fase de negociações preliminares, antes da formação do contrato preliminar, é possível que a Justiça considere que houve danos morais contra a candidata a vaga de trabalho. Destarte, deixar de contratar porque a candidata encontra-se grávida ou impossibilitar a contratação após o conhecimento da gravidez caracteriza ato discriminatório, crime e pode gerar a responsabilização na esfera trabalhista.

\subsection{O ROMPIMENTO DO CONTRATO PRELIMINAR EM VIRTUDE DE GRAVIDEZ}

Afora as situações da candidata não ser contratada pelo simples fato de estar grávida ou nem mesmo ter a possibilidade de passar por um processo seletivo, cumpre ainda tratar do 
caso em que a mulher, depois de recebida a notícia da seleção para a vaga, engravida e, noticiando o empregador, é informada que não mais poderá iniciar os trabalhos na empresa.

Como tratado anteriormente, a mulher que sofre discriminação em virtude da gravidez pode pleitear na justiça do trabalho indenização a título de danos morais. Essa se dá pelo simples fato do abalo à intimidade da mulher. Não há necessidade de que já tenha se firmado um contrato preliminar de trabalho.

Nesse item, por sua vez, passa-se a analisar a existência do contrato preliminar e o seu rompimento. Como já esclarecido, o pré-contrato de trabalho se forma a partir do momento em que o trabalhador é cientificado acerca da sua seleção para o emprego. A partir dai normalmente este é encaminhado para a abertura de conta bancária e realização de exames médicos.

É certo que, neste momento, o empregador não pode mais rescindir o contrato preliminar sem justificativa plausível, em virtude dos princípios da boa-fé e vinculação da proposta. Entretanto, vale lembrar que ainda que esta haja, caso seja demonstrada a existência de prejuízo ao trabalhador, haverá a necessidade de indenização a título de danos materiais ou morais, a depender do caso concreto.

Não há na doutrina e jurisprudência explanações acerca da indenização devida no caso de rompimento do contrato preliminar de trabalho em virtude da ciência da gravidez da candidata. Dessa forma, entende-se que para se chegar a uma resposta subsidiada de legitimidade e plausibilidade, necessário é visualizar o caso concreto a partir do estudo do pré-contrato de trabalho e suas responsabilidades, realizado anteriormente. Só assim a solução poderá ser vista pela sociedade como juridicamente válida.

Como estudado, a proposta feita ao candidato vincula o proponente. Essas são as considerações de Venosa. Segundo ele, a proposta é vinculante e tem efeitos concretos frente às partes (VENOSA, 2005, p. 547). Além da vinculação das partes, a proposta ainda vincula os termos estabelecidos no contrato preliminar. Dessa forma, as obrigações assumidas estão vinculadas ao contrato de trabalho celebrado e devem ser respeitadas.

Ademais, como abordado, a concepção de Zangrano (2008, p. 645) acerca do contrato preliminar é de este se forma quando da comunicação para o candidato da sua seleção para uma vaga de trabalho ou quando este é encaminhado para a realização de exames médicos admissionais. Assim, é possível se afirmar que quando uma mulher, ainda que grávida, recebe a informação acerca da sua seleção, o contrato preliminar já está formado.

É certo que nenhuma empresa fará um contrato preliminar condicionando o seu cumprimento a não existência de gravidez. Isso porque, essa atitude, por si só já caracterizaria discriminação. Isto posto, sendo firmado o contrato preliminar, sem a possibilidade de cláusula com condição resolutiva, é dever daquele que o firmou cumprir o pactuado pelo princípio da vinculação da proposta.

Segundo os estudos previamente mencionados, o rompimento do contrato preliminar, havendo prejuízo ao candidato, gera dever de indenizar. No caso em análise, não há dúvidas de que caso a candidata grávida tenha seu contrato preliminar rescindido e comprove danos 
sofridos, haverá o dever de reparação. Esse é o entendimento do Tribunal Regional do Trabalho da 17ª Região:

INDENIZAÇÃO POR DANO MORAL. PROMESSA DE EMPREGO. FASE PRE-CONTRATUAL. PRINCÍPIO DA BOA-FÉ OBJETIVA. 0 cancelamento da vaga, sem motivo justo, após a aprovação em todas as etapas do processo seletivo, configura lesão précontratual. Indenização por dano moral.Pré-contratação. Admissão frustrada em razão de comunicação de gravidez durante o processo seletivo. Ao constatar que a candidata ao cargo oferecido não foi contratada tão somente em razão da notificação à empresa reclamada de que estava grávida, plasma-se o caráter discriminatório na não admissão da trabalhadora, constituindo-se evidente afronta aos princípios constitucionais da dignidade humana, valor social do trabalho e da livre iniciativa, bem como da busca do pleno emprego, da função social da propriedade e da redução das desigualdades regionais e sociais, princípios sobre os quais se assenta a ordem econômica, conforme dispõe o art. 170 e também do art. 193, que estabelece que a ordem social tem como base o primado do trabalho e como objetivos o bem estar e a justiça sociais(grifos nossos) (TRT 17ª R.; RO 003470037.2013.5.17.0005; Terceira Turma; Rel. Des. Carlos Henrique Bezerra Leite; Julg. 21/10/2013; DOES 29/10/2013; Pág. 238).

Como é sabido, a estabilidade provisória da gestante estabelecida no artigo 10, II, b, $A D C T$, foi instituída pelo legislador para que as mulheres que estivessem com contrato de trabalho vigente tivessem direito à manutenção no emprego desde a confirmação da gravidez até cinco meses após o parto. A "confirmação" mencionada pelo constituinte é aquela íntima da mulher, confirmada através de exames, ou seja, decorrente do seu próprio corpo.

Não há posicionamento jurisprudencial e doutrinário acerca da obrigatoriedade do pagamento dos valores relativos ao tempo de estabilidade no caso de rompimento do contrato preliminar. Isso porque, inicialmente, a proteção legal está direcionada à manutenção no posto de trabalho.

Ainda que sem regulamentação legal, nesse estudo defende-se a aplicação da Lei mencionada aos contratos preliminares de trabalho. Isso significaria que, caso a empresa rompa o pré-contrato de trabalho de uma grávida, seria devido o pagamento dos salários relativos a todo o período estabilitário.

Essa sustentação se baseia no resguardo do valor social do trabalho, fundamento Constitucional (artigo 1ำ, IV, CF), no objetivo Constitucional de erradicar quaisquer formas de discriminação (artigo 3ำ IV, CF) e na proteção à maternidade consubstanciada na estabilidade concedida às gravidas desde a confirmação da gravidez até cinco meses após o parto (artigo 10, II, b, ADCT).

Assim, basta que a concepção se dê durante a realização dos exames, abertura de contas ou treinamentos, pois este é o marco inicial da estabilidade, mesmo que a confirmação para a gestante tenha ocorrido após a "dispensa". Este entendimento mantém a proteção almejada pelo Tribunal Superior do Trabalho à genitora e ao nascituro, independentemente de qualquer perspectiva objetiva.

\section{CONCLUSÃO}


Ao longo da história à proteção do trabalho da mulher passou por diversas fases. Inicialmente estas foram totalmente excluídas do mundo profissional, restringindo seus conhecimentos aos cuidados da casa e da família. Aos poucos passaram a desenvolver atividades artesanais, mas sem qualquer amparo legal. Com a revolução industrial, surgiu a necessidade de complementar a renda familiar, o que impulsionou trabalhadoras para o chão de fábrica.

Neste período, a falta de normatização do trabalho fez com que as mulheres de tornassem um grupo vulnerável, caracterizado por uma mão de obra barata e com pouca qualificação. Todo o trabalho era desenvolvido às margens da Lei, fazendo com que os abusos se tornassem cada vez mais assustadores. Jornadas exaustivas, ambientes insalubres e salários irrisórios faziam parte do suposto contrato de trabalho.

Posteriormente adveio a fase em que as censuras ao trabalho feminino se tornaram excessivas. Além da outorga marital, a exclusão do trabalho em certas atividades e sob certas condições fazia com que poucos empregadores se arriscassem a contratar mulheres. A proibição demasiada acabou por impossibilitar ainda mais o ingresso da mulher no mercado de trabalho.

As proibições, entretanto, foram paulatinamente se transformando em proteções. As normas impeditivas deixaram de existir, restando apenas aquelas que visavam efetivamente a guarita da saúde e do bem estar da mulher.

Todavia, apenas com a chegada da Constituição cidadã foi que as mulheres ganharam verdadeira isonomia social. Nesta foi declarada a igualdade entre homens e mulheres em todos os níveis, inclusive naqueles atinentes ao trabalho. Cita-se, por exemplo, a disposição do artigo $7^{\circ}$, inciso XXX que proíbe de diferença de salários, de exercício de funções e de critério de admissão por motivo de sexo.

Com a admissão da proteção do mercado de trabalho da mulher como matéria constitucional e com a determinação de criação de incentivos específicos para a efetividade da norma, o Brasil ingressou em nova fase do trabalho feminino. Atualmente vê-se que ciência trabalhista se volta à garantia do igual acesso e do incentivo do ingresso das mulheres ao mercado de trabalho através de normas que implantem proteções apenas onde efetivamente hajam diferenças.

Nesse sentido se coloca a estabilidade da gestante e a proteção do nascituro. A medida constitucional, ratificada pela Consolidação das Leis do Trabalho, fez com que a gravidez deixasse de ser vista como um empecilho para o trabalho. Hoje a proteção gestacional está consolidada nas normas atinentes à licença gestacional por período de 120 dias, mesmo no caso de adoção, transferência de função no período gestacional se for necessário em virtude de saúde, proibição da exigência de atestado de gravidez para admissão ou para manutenção do contrato de trabalho, disponibilização de ambiente adequado para a mãe amamentar seu filho.

Especificamente quanto a esta, a doutrina e a jurisprudência sempre caminharam no sentido de que sua aplicação se restringia às mulheres que tinham o contrato de trabalho firmado. Nesse estudo, porém defendeu-se a aplicação da norma de maneira analógica no caso do rompimento do contrato preliminar. 
Foi claramente demonstrado que o pré-contrato de trabalho desperta demasiada expectativa ao empregado, que se vê, na maioria das vezes, já contratado para a vaga. Em virtude disso, muitos abandonam outros empregos, realizam cursos, concretizam transferências e até mesmo fazem dívidas, com a certeza de que serão contratados.

Em virtude do caráter alimentício que envolve o emprego, de forma muito cuidadosa também deve ser analisado o contrato preliminar de trabalho. Havendo prejuízos ao trabalhador, é certo o dever de indenizar. Sendo certo o prejuízo social, financeiro e moral advindo da dispensa de uma grávida, cabe ao empregador efetivar a contratação e respeitar o período de estabilidade ou indenizar nos salários correspondentes a todo o período estabilitário. Trata-se da ampliação da interpretação das normas já existentes acerca da proteção do trabalho da mulher e que garantirá ainda mais a manutenção dos empregos e a saúde do nascituro.

Por fim, defende-se ainda a indenização dos prejuízos morais no caso da proibição de participação de processo seletivo em virtude de gravidez. Ainda que não haja menção do empregador nesse sentido, sendo caracterizada a discriminação é objetiva a responsabilidade de indenizar. É preciso exigir que a empresa cumpra efetivamente sua função social, preservando os valores sociais do trabalho e promovendo o bem de todos, sem preconceitos e discriminação em razão de sexo ou condição, fundamentos da República Federativa do Brasil.

\section{REFERÊNCIAS}

BARACAT, Eduardo Milléo. A boa-fé no direito individual do trabalho. São Paulo: LTr, 2003.

BARROS, Alice Monteiro de. Curso de Direito do Trabalho. 5 ed. LTr: 2009.

BRASIL. Código Civil, Lei 10.406, de 10 de janeiro de 2002. 1. ed. São Paulo: Revista dos Tribunais, 2002.

BRASIL. Tribunal Regional do Trabalho (1. Região). Recurso Ordinário ㄲo 000169575.2012.5.01.0014. Recorrente: CBX Locação de Equipamentos LTDA. Recorridos: Natália Fonseca da Silva e Grupo EBC Brasil S/A. Relator: Flávio Ernesto Rodrigues Silva. Rio de Janeiro, 17 de junho de 2015.

CAHALI, Yussef Said. Dano Moral. Revista dos Tribunais. 2 ed. 1998.

CAVALIERI FILHO, Sérgio Cavalieri. Programa de Responsabilidade Civil. 8. ed. São Paulo: Atlas, 2009.

FISCHER, Hans Albrecht. A reparação dos danos no direito civil. Tradução de Antônio de Arruda Ferrer Correia. São Paulo: Saraiva, 1938.

GONÇALVES, Carlos Roberto. Direito Civil Brasileiro: contratos e atos unilaterais. 7. ed. São Paulo: Saraiva, 2010. v. 3.

DALLEGRAVE NETO, José Affonso. Responsabilidade civil no direito do trabalho. 3. ed. São Paulo: LTr, 2008.

DINIZ, Maria Helena. Dicionário Jurídico. São Paulo: Saraiva, 2013. v. 1. 
KANEOYA, Emerson Yukio. Pré-contrato na justiça do Trabalho. 2010. 29 fls. Artigo (Especialização em Direito) - Faculdades Metropolitanas Unidas, São Paulo, 2010.

MARANHÃO, Délio. Instituições de Direito do Trabalho. 12. ed. São Paulo: LTr, 2000.

MONTEIRO, Washington de Barros. Curso de Direito Civil: direito das obrigações. 34. ed. São Paulo: Saraiva, 2003. v. 5.

NASCIMENTO, Amauri Mascaro. Iniciação ao Direito do Trabalho. 22 ed. São Paulo: LTr, 1996.

NORONHA, Fernando. Direito das obrigações: fundamentos do direito das obrigações. Introdução à responsabilidade civil. São Paulo: Saraiva, 2003. v. 1.

NUNES JUNIOR, Vidal Serrano. A proteção constitucional da informação e o direito a crítica jornalística. São Paulo: FTD, 1997.

PRATA, Ana. Notas sobre a responsabilidade pré-contratual. Coimbra: Almeidina, 2005.

PORTUGAL. Regime jurídico do contrato individual de trabalho. Decreto-Lei n. 49.408. Novembro 24, 1969.

OLIVEIRA, Paulo Eduardo. O dano pessoal no direito do trabalho. São Paulo: LTr, 2002.

RIBEIRO. Leonardo Ferres da Silva. Compromisso de compra e venda - constitui-se, ou não, em contrato preliminar? Revista dos Tribunais, s/l, v. 814, ano 92, p. 44-62, ago. 2003.

SILVA PEREIRA, Caio Mário da. Instituições de Direito Civil. 11. ed. Rio de Janeiro: Revista Forense, 2004. v. 3.

SILVA, José Afonso da. Curso de direito constitucional positivo. 19. ed. São Paulo: Malheiros, 2001.

VENOSA, Silvio de Salvo. Direito Civil: teoria geral das obrigações e teoria geral dos contratos. 5. ed. São Paulo: Atlas, 2005. v. 2.

ZANGRANDO, Carlos Henrique da Silva. Curso de Direito do Trabalho. São Paulo: LTr, 2008. v. 1. 